\title{
PENERAPAN REKAYASAN ALAT PENGHANCUR SAMPAH DALAM MENUNJANG PENGELOLAAN SAMPAH
}

\author{
Asep Tata Gunawan'), Zaeni Budiono ${ }^{1)}$ \\ Poltekkes Kemenkes Semarang
}

\begin{abstract}
Abstrak
Kampus 7 Politeknik Kesehatan Kemenkes Semarang, merupakan salah instansi pendidikan yang terintegrasi dengan kantin, perumahan dosen serta memiliki lahan terbuka yang mencapai 2,3 ha terdapat timbulan sampah organik rata-rata $4 \mathrm{~m}^{3} /$ minggu dan sampah an-organik rerata $0,85 \mathrm{~m}^{3} / \mathrm{minggu}$ dengan dominasi plastik (GELISH, 2019). Jurusan Kesehatan Lingkungan dan memiliki sumber daya manusia (SDM) yang mumpuni dalam bidang pengolahan sampah telah merintis unit percontohan komposter dengan metode run way yang bersusun dalam 10 bak. Upaya menangai sampah organik telah terwujud dalam hasil produk pengolahan berupa kompos organik. Seiring berjalannya kegiatan pengomposan, dilakukan kegiatan evaluasi kegiatan. Hasil evaluasi terdapat catatan penting pada proses pengomposan yang dilakukan, seperti proses pembalikan sampah yang terlalu banyak, pemindahan sampah pada bak pengomposan yang banyak, keluhan bau yang menyengat dan risiko tertusuk dari sampah kaleng/ kaca dan hasil kompos kurang maksimal. Semua kondisi tersebut disebabkan karena kegiatan masih dilakukan secara manual oleh tenaga kebersihan. Desain penelitian ini adalah adalah pra eksperimen dengan rancangan penelitian Post Test Only Design.Lokasi penelitian ini dilakukan di lokasi pengolahan sampah (komposter) di Kampus 7 Poltekkes Kemenkes Semarang. Dalam penelitian ini populasi yang dimaksud oleh peneliti adalah seluruh warga kampus 7 dan seluruh timbulan sampah. Sampel penelitian ini adalah sampah plastik yang terdapat pada bak pengolahan kompos, hasil pemanenan sampah plastik dengan rata-rata volume sebesar $0,3 \mathrm{~m}^{3} / \mathrm{minggu}$. Analisis data yang digunakan dalam penelitian ini adalah analisis deskriptif dari hasil penghancuran sampah plastik. Alat pengahancur sampah yang telah dibuat memiliki kemampu dalam mencacah sampah mencapai $<5 \mathrm{~cm}$, dengan kapasitas penghancuran sekitar $10 \mathrm{~kg} / 7,5$ menit $=80 \mathrm{Kg} / \mathrm{jam}(10 \mathrm{~kg}$ paslik $=5 \mathrm{karung}$ sampah plastic $)$. Maka mesin tersebut mampu menghancurkan plastic sekitar 0,083 m3/jam. Jadi utk menghancurkan sampah plastik kampus 7 sekitar 0,3 m3/mg dibutuhkan waktu sekitar 3,6 jam. Diperlukannya penyesuaian lanjutan terhadap kemampuan mata pisau. Perlu ditingkatkan kemampuan motor penggerak, sehingga hasil pencacahan akan lebih cepat.
\end{abstract}

Kata Kunci : Sampah, Alat penghancur sampah.

\section{Abstrack}

Campus 7 Health Polytechnic of the Ministry of Health Semarang, is one of the educational institutions integrated with the canteen, lecturer housing and has open land that reaches 2.3 ha there is organic waste generation an average of $4 \mathrm{m3} /$ week and average inorganic waste is $0.85 \mathrm{~m} 3$ / week with plastic dominance (GELISH, 2019). The Department of Environmental Health and having qualified human resources in the field of waste management has pioneered a composter pilot unit with a runway method which is arranged in 10 tanks. Efforts to deal with organic waste have been realized in the results of processing products in the form of organic compost. As composting progressed, evaluation of activities was carried out. The results of the evaluation have important notes on the composting process carried out, such as the process of overturning waste too much, the removal of rubbish in a lot of composting tanks, complaints of strong odors and the risk of being punctured by cans/glass waste and less compost yield. All of these conditions were caused because the activities were still carried out manually by cleaning staff. The design of this study was a pre-experimental research design with a Post Test Only Design. The location of this study was carried out at a waste treatment location (composter) at Campus 7 of the Polytechnic of the Ministry of Health Semarang. In this study the population referred to by the researchers is all residents of campus 7 and all waste generation. The sample of this research was plastic waste in compost processing tubs, harvesting plastic waste with an average volume of $0.3 \mathrm{~m} 3$ / week. Analysis of the data used in this study is a descriptive analysis of the results of the destruction of plastic waste. The waste crushing tool that has been made has the ability to chop up waste $<5 \mathrm{~cm}$, with a crushing capacity of about $10 \mathrm{~kg} / 7.5$ minutes $=80 \mathrm{~kg} / \mathrm{hour}(10 \mathrm{~kg}$ post-load $=5$ plastic sacks of garbage $)$. Then the machine is able to destroy plastic around $0.083 \mathrm{~m} 3 /$ hour. So to destroy Campus 7 plastic waste around $0.3 \mathrm{~m} 3 / \mathrm{mg}$ it takes around 3.6 hours. Further adjustments are needed to the ability of the blade. Need to increase the ability of the motor drive, so that the results of enumeration will be faster.

Keywords: Garbage, Garbage Crusher. 


\section{PENDAHULUAN}

Sampah merupakan sumber penyakit, baik secara langsung maupun secara tak langsung. Secara langsung sampah merupakan tempat berkembangnya berbagai parasit, bakteri dan patogen; sedangkan secara tak langsung sampah merupakan sarang berbagai vektor (pembawa penyakit) seperti tikus, kecoa, lalat dan nyamuk. Sampah yang membusuk, maupun kaleng, botol, plastik, merupakan sarang patogen dan vektor penyakit. Berbagai penyakit yang dapat muncul karena sampah yang tidak dikelola dengan baik adalah diare, disentri, cacingan, malaria, kaki gajah (elephantiasis) dan demam berdarah. Penyakit-penyakit ini merupakan ancaman bagi manusia, yang dapat menimbulkan kematian. (Imran SL Tobing, 2005).

Dalam perkembangannya, ternyata permasalahan sampah di Indonesia menjadi lebih kompleks dan meluas terutama terkait isu pencemaran sampah di laut. Hasil penelitian Jambeck, Jena R, et al, (2015) menyatakan bahwa potensi sampah plastik yang ada di lautan Indonesia mencapai 187,2 juta ton/tahun. Dengan hasil penelitian tersebut menempatkan Indonesia menjadi negara kedua terbesar yang menyumbang sampah setelah Tiongkok, disusul filipina, Vietnam, dan Sri Lanka. Menurut Riset Greenation, organisasi non pemerintah yang telah 10 tahunmengikuti isue persampahan, satu orang Indonesia mengasilkan 700 kantong plastik per tahun (Kementerian Pekerjaan Umum dan Perumahan Rakyat, 2016).

Sumber penimbulan sampah dapat berasal dari berbagai macam tempat, seperti rumah tangga, perkantoran, perdagangan, industri, sisa konstruksi, jalan raya, perikanan/ peternakan dan pertambangan. Dan sampah yang dihasilkan bervariasi berdasarkan tempat penimbulannya. Untuk penanganan sampah yang telah umum dilakukan adalah pembuangan langsung ke Tempat Pembuangan Akhir (TPA) secara open dumping.
Kampus 7 Politeknik Kesehatan Kemenkes Semarang, merupakan salah instansi pendidikan yang terintegrasi dengan kantin, perumahan dosen serta memiliki lahan terbuka yang mencapai 2,3 ha terdapat timbulan sampah organik rata-rata 4 $\mathrm{m}^{3} /$ minggu dan sampah an-organik rerata 0,85 $\mathrm{m}^{3} /$ minggu dengan dominasi plastik (GELISH, 2019). Untuk menanggulangi akumulasi sampah, diperlukan pengoptimalan Pengolahan terhadap sampah. Membuang sampah dengan cara biasa yaitu dengan sekadar membuang sampah tersebut pada tempat penampungan sementara (TPS) yang kemudian dibuang ke pembuangan akhir (TPA). Hal itu dirasa masih kurang efektif dalam mengatasi permasalahan yang ada, dengan memperhatikan surat edaran bupati nomor: 660.1/7776/2018, dalam surat edaran tersebut bupati secara tegas mengintruksikan penutupan TPA yang ada terhitung 2 Januari 2019 dan mendesak pengelolaan sampah melalui Kelompok Swadaya Masyarakat (KSM) dalam pengelolaan sampah 3R.

Kampus 7 sebagai institusi pendidikan yang didalamnya terdapat Jurusan Kesehatan Lingkungan dan memiliki sumber daya manusia (SDM) yang mumpuni dalam bidang pengolahan sampah telah merintis unit percontohan komposter dengan metode run way yang bersusun dalam 10 bak. Upaya menangai sampah organik telah terwujud dalam hasil produk pengolahan berupa kompos organik. Seiring berjalannya kegiatan pengomposan, dilakukan kegiatan evaluasi kegiatan. Hasil evaluasi terdapat catatan penting pada proses pengomposan yang dilakukan, seperti proses pembalikan sampah yang terlalu banyak, pemindahan sampah pada bak pengomposan yang banyak, keluhan bau yang menyengat dan risiko tertusuk dari sampah kaleng/ kaca dan hasil kompos kurang maksimal. Semua kondisi tersebut disebabkan karena kegiatan masih dilakukan secara manual oleh tenaga kebersihan. 


\section{METODA}

Desain penelitian ini adalah adalah pra eksperimen dengan rancangan penelitian Post Test Only Design.Lokasi penelitian ini dilakukan di lokasi pengolahan sampah (komposter) di Kampus 7 Poltekkes Kemenkes Semarang.

Dalam penelitian ini populasi yang dimaksud oleh peneliti adalah seluruh warga kampus 7 dan seluruh timbulan sampah. Sampel penelitian ini adalah sampah plastik yang terdapat pada bak pengolahan kompos, hasil pemanenan sampah plastik dengan ratarata volume sebesar $0,3 \mathrm{~m}^{3} /$ minggu.

Data yang dikumpulkan kemudian ditabulasi dan dianalisis. Analisis data yang digunakan dalam penelitian ini adalah analisis deskriptif dari hasil penghancuran sampah plastik.

III. HASIL

\begin{tabular}{|c|l|l|l|}
\hline No & Waktu & Kegiatan & Keterangan \\
\hline 1. & $\begin{array}{l}\text { Juli } \\
2019\end{array}$ & $\begin{array}{l}\text { Desain alat } \\
\text { penghancur } \\
\text { sampah } \\
\text { plastik }\end{array}$ \\
\hline 2. & $\begin{array}{l}\text { Agustus } \\
2019\end{array}$ & $\begin{array}{l}\text { Pembelian } \\
\text { bahan baku } \\
\text { pembuatan } \\
\text { alat }\end{array}$ & \\
\hline
\end{tabular}

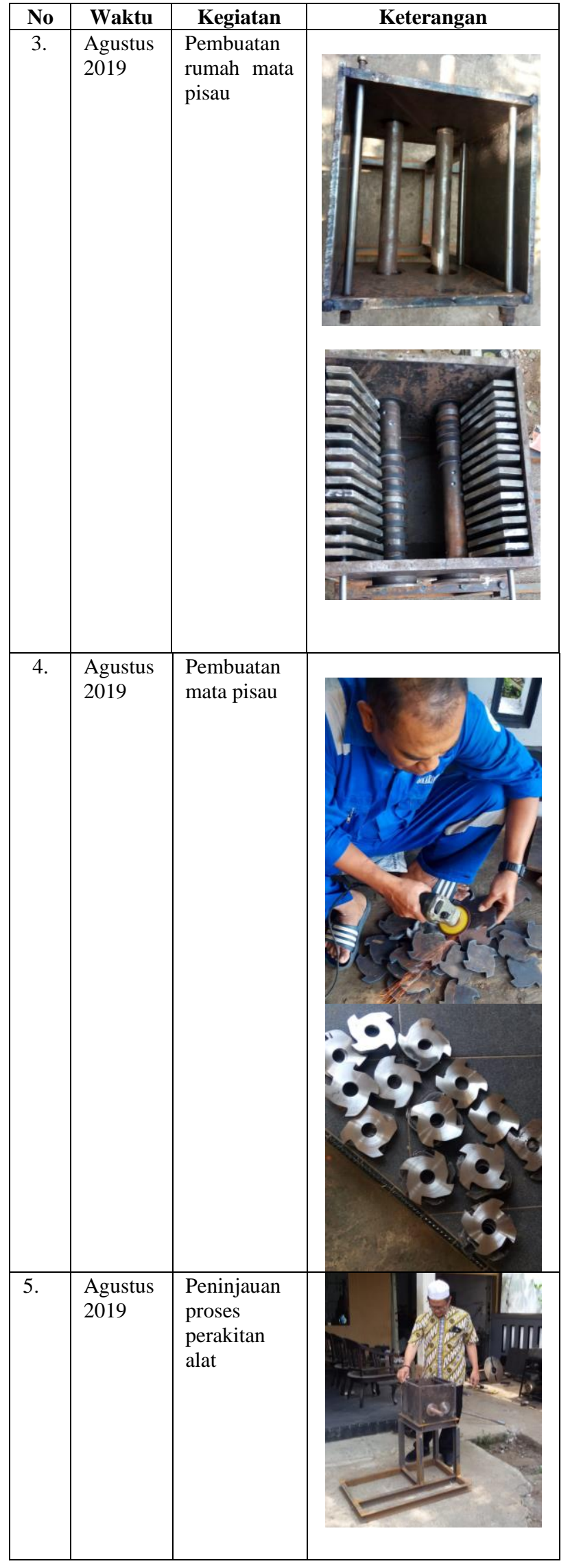




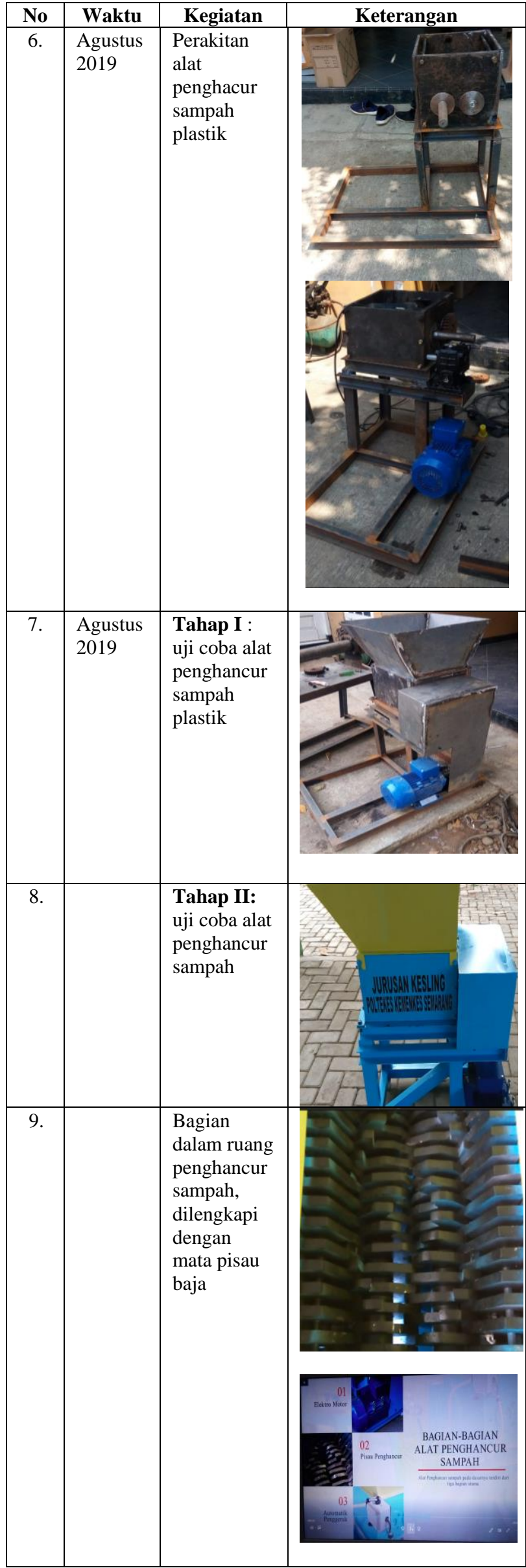

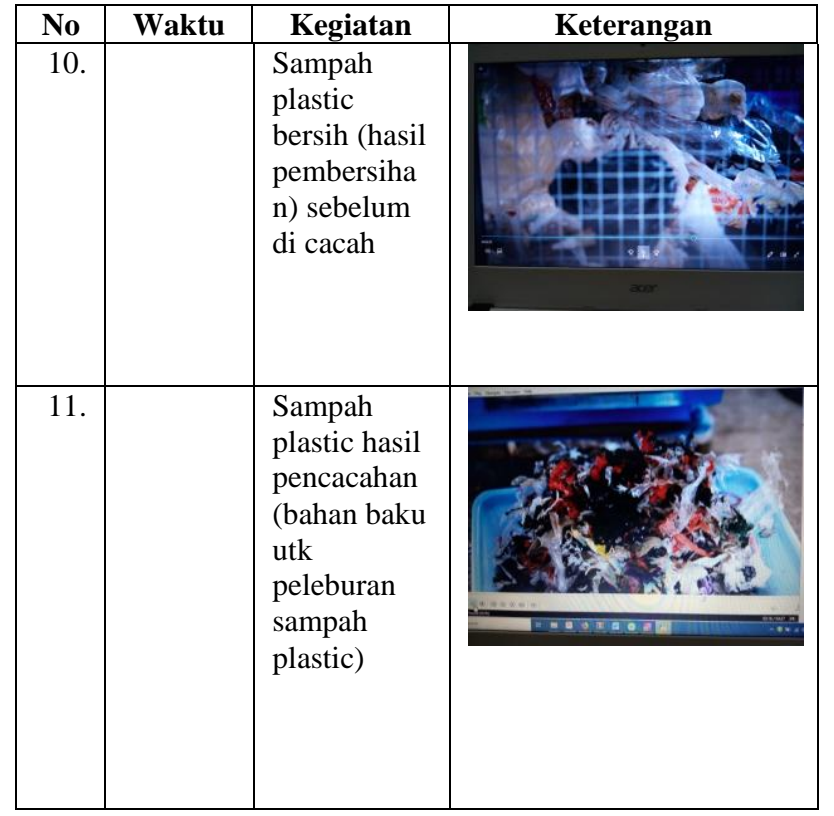

\begin{tabular}{|l|l|}
\hline \multicolumn{2}{|c|}{ Pencacah Sampah plastic } \\
\hline Volume alat & $: 85$ X $60 \times 90 \mathrm{~cm}$ \\
\hline Bobot alat & $: 260 \mathrm{Kg}$ \\
\hline Power AC & $: 380 \mathrm{~V} / 5 \mathrm{HP}$ \\
\hline Kapasitas motor penggerak & $: 1425 . \mathrm{Rpm}$ \\
\hline Kapasitas mata pisau & $: 30 \mathrm{rpm}$ \\
\hline Beban kerja & $\begin{array}{l}: 10 \mathrm{~kg} / 7,5 \text { menit }=80 \\
\mathrm{Kg} / \mathrm{jam}\end{array}$ \\
\hline
\end{tabular}

1. Kelebihan alat

a. Alat penghancur sampah telah dilengkapi dengan switch pemutar balik otomatis untuk mencegah terjadinya macet pada ruang mata pisau

b. Alat penghancur sampah dilengkapi dengan pengaman kerja pada karet pemutar untuk meminimalisir terjadinya kecelakaan pada pekerja

c. Mampu mencacah sampah sampai dengan ukuran $5 \mathrm{~cm}$

2. Kekurangan alat

a. Mata pisau cepat tumpul karena sampah dalam kondisi basah

b. Terjadi kemacetan putaran pisau penghancur smapah plastik 


\section{PEMBAHASAN}

Hasil pengujian alat ini mendapatkan desain yang memenuhi kebutuhan dalam pengolahan sampah, utamanya adalah penghancuran sampah. Penghancuran sampah yang dilakukan meliputi sampah organik berupa dedaunan, batang/ ranting pohon, bunga cemara serta sampah anorganik lain seperti plastik, dan kaleng. Pada penelitian ini akan difouskan pada sampah plastic.

Hasil dari proses penghancuran berhasil mengurangi ukuran, sampah plastik dengan rata-rata ukuran hasil penghancuran adalah $<5 \mathrm{~cm}$, hal ini menunjukkan bahwa kemampuan alat telah efektif dalam mendukung percepatan proses lanjutan pemanfaatan sampah plastic.

Hasil uji fungsi pertama ditemukan adanya kemacetan pada pisau penghancur sehingga diperlukan revisi pada outomatik putaran pisau penghancur, perbaikan dudukan reducer dan evaluasi kekuatan putaran motor

Pada uji fungsi kedua penghacur sampah plastic berjalan dengan lancarr sesuai yg direncanakan dengan kapasitas penghancuran sekitar $10 \mathrm{~kg} / 7,5$ menit $=80$ $\mathrm{Kg} / \mathrm{jam}$ (10 kg paslik $=5$ karung sampah plastic). Dengan massa jenis plastic 0,96 $\mathrm{g} / \mathrm{cm}^{3}\left(960 \mathrm{~kg} / \mathrm{m}^{3}\right)$ maka mesin tersebut mampu menghancurkan plastic sekitar 0,083 $\mathrm{m} 3 / \mathrm{jam}$. Jadi utk menghancurkan sampah plastik kampus 7 sekitar $0,3 \mathrm{~m} 3 / \mathrm{mg}$ dibutuhkan waktu sekitar 3,6 jam. Jadi alat tersebut mampu menyelesai penghancuran sampah plastic di kampus 7. Hasil penghancuran sampah plastic menjadi bahan baku peleburan sampah plastic.
Adapun dari kekurangan yang ada bisa direncakan rekasa lebih lanjut yaitu :

- Perlu pemasangan outomatik putaran mesin, sehingga kalau terjadi kemacetan penghancuran, mesin penghancur akan outomatis berputar balik utk menyesuaikan dengan kondisi bahan yg sedang di hancurkan.

- Penguatan dan pengontrolan sebelum digunakan dudukan mesin reducer sehingga putaran mesin bisa stabil.

- Peningkatan kekutan motor putar menjadi 5 HP

Dari hasil pengamatan kerja alat tersebut maka ada beberapa langkah kerja utk pengoprasian alat tersebut :

1. Mengecek kondisi mesin

2. Menghidupkan mesin penghancur

3. Menyiapkan bahan baku sampah plastic yang sudah dibersihkan

4. Memasukan sampah plastic kedalam mesin penghancur secara bertahap.

5. Apabila mesin macet, segera mesin matikan, kemudian hidupkan mesin kearah yang kebalikannya. Apabila sudah lancar bahan plastic lainnya bisa dimasukan kembali.

6. Manampung plastic hasil penghancuran, selanjutnya sebagai bahan untuk penghancuran.

\section{SIMPULAN DAN SARAN :}

A. SIMPULAN

1. Desain alat penghancuran sampah plastik telah memenuhi kebutuhan dalam mendukung proses pengolahan sampah plastic di kampus 7 Poltekkes Kemenkes Semarang di Purwokerto. 
2. Kemampuan alat dalam mencacah sampah mencapai $<5$ cm, dengan kapasitas penghancuran sekitar $10 \mathrm{~kg} / 7,5$ menit $=80 \mathrm{Kg} / \mathrm{jam}(10 \mathrm{~kg}$ paslik $=5$ karung sampah plastic). Maka mesin tersebut mampu menghancurkan plastic sekitar 0,083 m3/jam. Jadi utk menghancurkan sampah plastik kampus 7 sekitar $0,3 \quad \mathrm{~m} 3 / \mathrm{mg}$ dibutuhkan waktu sekitar 3,6 jam.

B. SARAN

1. Diperlukannya penyesuaian lanjutan terhadap kemampuan mata pisau

2. Meningkatkan kemampuan motor penggerak, sehingga hasil pencacahan akan lebih cepat.

\section{DAFTAR PUSTAKA}

Anonim. Dasar dasar Sistem Pengelolaan Persampahan pplpdinciptakaru.jatengprov.go.id accessed January 2018.

Bandura, Albert. 1997. SELF-EFFICACY: The Exercise of Control. Stanford University. New York. W.H. Freeman and Company.

Creswell, J.W. 1994. Research Design Qualitative and Quantitative Approaches. Sage Publication : London.

Creswell, J.W and Dana L Miller. 2000. Determining Validity in Qualitative Inquiry. Theory Into Practice Vol. 39, No. 3, Getting Good Qualitative Data to Improve Educational Practice (Summer, 2000), pp. 124-130.
Enri Damanhuri dan Tri Padmi. 2010. Diktat Pengelolaan Sampah. ITB : Bandung.

Hill, Tosi., Caroll, SJ. 1997. Organizational Theory and management : A Macro Approach. John Willey and Sons Inc : New York.

Jenna R.Jambeck, Roland Geyer, Chris Wilcox, Theodore R.Sieger, Miriam Perryman, Anthony Andrady, Ramani Narayan, Kara Lavender Law. 2015. Plastic waste inputs from land into the ocean. Sciencemag 13 February 2015 Vol 374 Issue 6223.

Okut Ookumu, J. And Nyenje, R. 2011. Municipal Solid Waste Management Under Decentralization in Uganda. Habitat International Volume 35, Issue 4 , October 2011, Pages 537-543.

Peraturan Pemerintah Republik Indonesia, nomor 17 Tahun 2010, tentang Pengelolaan dan Penyelenggaraan Pendidikan. Jakarta.

Pemerintah Kota Yogyakarta, 2014, Profil Kota Yogyakarta, Yogyakarta : Pemkot Yogyakarta.

Siti Marwati. 2013. Pengelolaan Sampah Mandiri Berbasis Masyarakat. Jurusan Pendidikan Kimia FMIPA UNY.

Slamet Santoso SP. 2010. Dampak Negatif Sampah Terhadap Lingkungan dan Upaya Mengatasinya. Fakultas Biologi UNSOED.

Tobing, I. S. (2005). Dampak Sampah Terhadap Kesehatan Lingkungan dan Manusia. Jakarta: Fakultas Biologi Universitas Nasional, 1-9.

Undang-Undang Nomor 18 Tahun 2008 Tentang Pengelolaan Sampah.

Willie Susuki, Air Handono Ramelan dan Dwi Aries Himawanto. 2016. Penanganan Sampah Berdasarkan Karakteristik Sampah di Kota Surakarta. FKIP UNS.

Yin, R. 1994. Case Studi research : Design and methods (2nd ed). Sage Publications, Thousand Oaks, CA. 